\title{
Antimicrobial Food Packaging to Enhance Food Safety: Current Developments and Future Challenges
}

\section{Sunil Mangalassary*}

Food Science and Technology Program, School of Kinesiology and Nutritional Science, California State University, Los Angeles, USA

The post-processing contamination is one of the major causes of foodborne illness and the associated food product recalls; a major public health issue and an economic burden for the food industry [1]. Therefore, post-processing antimicrobial interventions are gaining significance in order to control the growth of bacteria that contaminate the food product after the primary lethal treatment. Packaging of foods is one of the final steps in food processing before storage and consumption and therefore is a critical step for incorporating antimicrobial mechanisms especially to control the post-processing contamination. Antimicrobial packaging is a promising form of active packaging to improve safety and shelf-life of food products. In antimicrobial packaging, agents may be coated, incorporated, immobilized, or surface modified onto packaging materials [2]. Many compounds such as organic acids, bacteriocins, enzymes, spices and polysaccharides (chitosan) have been tried in antimicrobial packaging with varying degree of success.

The three basic categories of antimicrobial packaging systems include incorporation of antimicrobial substances into a sachet connected to the package from which the volatile bioactive substance is released during further storage; direct incorporation of antimicrobial agent into the packaging film; coating of packaging with a matrix that acts as a carrier for the antimicrobial agent [3]. Non-volatile antimicrobial substances must contact the surface of the food, so that the antimicrobial substances can diffuse to the surface of the food product. Therefore, diffusion of incorporated antimicrobial agents from the packaging material to the surface of the food is crucial in exerting the antimicrobial activity [4]. The rate of diffusion of the agent also plays a role in terms of sustaining the antimicrobial activity on the food product. A few research studies examined the ways to affect a controlled release of antimicrobial agents from the polymer matrix [5-7]. Nano composite films containing antimicrobial agents with improved mechanical, thermal, optical and physicochemical properties are studied for more effective delivery of the agents [8,9].

The demand for natural preservative/antimicrobial agents is more than ever at present. Many natural antimicrobial agents like bacteriocins, spices, and enzymes have been effectively incorporated into biodegradable films [10-12].

Most of the studies on antimicrobial packaging mainly focused on the initial screening of newly developed films for antimicrobial activity in laboratory media and quantifying the bacterial reductions obtained during storage for different types of packaged food products. In order to commercialize the application, it is really important to know the variation in antibacterial activity of the agents when incorporated into the packaging film from its original activity in order to establish the levels that need to be incorporated for effective bacterial inhibition. This knowledge about the variation in antimicrobial activity will also be useful to control the factors in the production of antimicrobial films that may reduce the antimicrobial activity of the compounds. Another important aspect that needs to be investigated from an industrial application perspective is the retention of antimicrobial activity of packaging films during storage. A major difficulty in commercializing this technology is the susceptibility of the majority of the antimicrobial compounds to the high processing temperature used for the production of packaging polymers. Development of effective systems to successfully coat the antimicrobial compounds onto the fully formed polymer material is a way to solve this problem.

Development of biopolymers containing natural antimicrobial agents and their effective commercialization will be a great step towards attaining sustainability in food packaging applications.

\section{References}

1. Mangalassary S, Han I, Rieck J, Acton J, Jiang X, et al. (2007) Effect of combining nisin and/or lysozyme with in-package pasteurization on thermal inactivation of Listeria monocytogenes in ready-to-eat turkey bologna. J Food Prot 70: 2503-2511.

2. Pérez-Pérez C, Regalado-González C, Rodríguez-Rodríguez CA, BarbosaRodríguez JR, Villaseñor-Ortega F (2006) Incorporation of antimicrobial agents in food packaging films and coatings. Advances in Agricultural and Food Biotechnology 193-216.

3. Appendini P, Hotchkiss JH (2002) Review of antimicrobial packaging. Innov Food Sci Emerg Technol 3: 113-126.

4. Cooksey K (2005) Effectiveness of antimicrobial food packaging materials Food Addit Contam 22: 980-987.

5. Del Nobile MA, Conte A, Incoronato AL, Panza O (2008) Antimicrobial efficacy and release kinetics of thymol from zein films. J Food Eng 89: 57-63.

6. Mastromatteo M, Barbuzzi G, Conte A, Del Nobile MA (2009) Controlled release of thymol from zein based film. Innov Food Sci Emerg Technol 10: 222-227.

7. Ouattara B, Simard RE, Piette G, Begin A, Holley RA (2000) Diffusion of acetic and propionic acids from chitosan-based antimicrobial packaging films. J Food Sci 65: 768-773.

8. Rhim JW, Ng PK (2007) Natural biopolymer-based nanocomposite films for packaging applications. Crit Rev Food Sci Nutr 47: 411-433.

9. Tunç S, Duman O (2011) Preparation of active antimicrobial methyl cellulose/

${ }^{*}$ Corresponding author: Sunil Mangalassary, Assistant Professor, Food Science and Technology Program, School of Kinesiology and Nutritional Science, Califor nia State University, Los Angeles, USA, Tel: 864-650-4102; E-mail: smangal@ exchange.calstatela.edu

Received June 11, 2012; Accepted June 13, 2012; Published June 15, 2012

Citation: Sunil M (2012) Antimicrobial Food Packaging to Enhance Food Safety Current Developments and Future Challenges. J Food Process Technol 3:e103. doi:10.4172/2157-7110.1000e103

Copyright: (C) 2012 Sunil M . This is an open-access article distributed under the terms of the Creative Commons Attribution License, which permits unrestricted use, distribution, and reproduction in any medium, provided the original author and source are credited. 
Citation: Sunil M (2012) Antimicrobial Food Packaging to Enhance Food Safety: Current Developments and Future Challenges. J Food Process Technol 3:e103. doi:10.4172/2157-7110.1000e103

Page 2 of 2

carvacrol/montmorillonite nanocomposite films and investigation of carvacrol release. LWT - Food Science and Technology 44: 465-472

10. Pelissari FM, Grossmann MV, Yamashita F, Pineda EA (2009) Antimicrobial, mechanical, and barrier properties of cassava starch-chitosan films incorporated with oregano essential oil. J Agric Food Chem 57: 7499-7504
11. Padgett T, Han IY, Dawson PL (1998) Incorporation of food-grade antimicrobial compounds into biodegradable packaging films. J Food Prot 61:1330-1335.

12. Salmieri S, Lacroix M (2006) Physicochemical properties of alginate/ polycaprolactone-based films containing essential oils. J Agric Food Chem 54 10205-10214 